\title{
Multidisciplinary model for hospital-territory integrated management of patient with bone fragility: primary and secondary prevention of fractures according to severity and complexity
}

\author{
C. Caffetti ${ }^{\star}$, L. Bogliolo» ${ }^{2 \star}$ G. Giuffrè ${ }^{3}$, A. Sozzi ${ }^{4}$, L. Degli Esposti ${ }^{5}$, E. Bellis ${ }^{2}$, \\ C. Montecucco ${ }^{2}$, F. Reitano ${ }^{6}$, A. Triarico7, S. Silva ${ }^{8}$, M. Bejor ${ }^{1}$, A. Muzzi $^{9}$, \\ P. Mirabile ${ }^{10}$, N. Ramaioli11, M. Brait ${ }^{12}$ \\ 'U.O.C. Riabilitazione Specialistica di Voghera, ASST Pavia; ${ }^{2}$ U.O.C. Reumatologia, Fondazione IRCCS

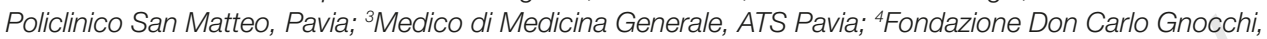 \\ ONLUS Centro Santa Maria alle Fonti, Salice Terme, Pavia; ${ }^{5}$ CliCon S.r.l. - Health, Economics \\ \& Outcomes Research, Pavia; ${ }^{6}$ Direzione Sanitaria Aziendale, ASST Pavia; 'Direzione Sanitaria, Fondazione \\ IRCCS Policlinico San Matteo, Pavia; ${ }^{8}$ Direzione Sanitaria, ATS Pavia; ${ }^{9}$ Software developer, freelance; \\ ${ }^{10}$ Direzione Medica di Presidio, Fondazione IRCCS Policlinico San Matteo, Pavia; ${ }^{11}$ UOS Accreditamento \\ e Qualità, ASST Pavia; ${ }^{12}$ Direzione Generale, ASST Pavia, Italia; *First co-authors; ${ }^{\circledR}$ Corresponding author
}

\section{SUMMARY}

The aim of this study was to promote the construction of a real network and a shared diagnostic and therapeutic management model between hospitals and out-of-hospital healthcare services to capture as many patients with bone fragility as possible.

Starting from the analysis of the clinical competences present in the province of Pavia, the bone specialists (BSs) organized some educational events involving both general practitioners (GPs) and hospital specialists. The Fracture Liaison Service (FLS) model, the revision of Note 79, the national plan for chronicity and the health reform of the Lombardy Regional Authority supported the structure of our model, in which the roles of clinicians are well defined and based on the complexity and severity of patients. In our method the GP has a central role as clinical manager, facilitating patient management and communication between the specialists and the BS.

In January 2019, the Therapeutic Care Diagnostic Path (PDTA) shared between 2 bone specialists (BSs), 9 GPs, as reference treaters, and a multidisciplinary group of 25 specialists of the Province of Pavia was defined. The strategic directions of the two largest public hospitals in Pavia have supported the PDTA, which was validated by the quality departments of the hospitals themselves. Finally, sixty GPs belonging to the network have joined the PDTA.

This model is the first example of integrated management between hospitals and out-of-hospital healthcare services for the primary and secondary prevention of fragility fractures (FF), where the GPs play a pivotal role as managers and supervisors to ensure proper care to chronic patients according to their levels of severity.

Key words: Osteoporosis; fragility fractures; management; network; sustainability.

Reumatismo, 2020; 72 (2): 75-85

\section{INTRODUCTION}

steoporosis (OP) is a chronic disease characterized by reduced bone mineral density (BMD) and altered microarchitecture, leading to an increased risk of fragility fractures (FF) (1), defined as lowenergy fractures (2), which are accompanied by high hospital admission rates (3), disability, mortality $(4,5)$ and significant direct and indirect costs comparable to those of myocardial infarction and stroke $(6,7)$. Due to the increased number of elderly people in Italy and Europe, we expect a higher number of affected patients who will need treatment. Such trend is expected to lead to a cost of 11.9 billion euros in 2030 with an increase of about $26 \%$ (8).

Despite the known prevalence data $(9,10)$, the healthcare and economic impact $(7,11$,
Corresponding author: Laura Bogliolo UOC Reumatologia,

Fondazione IRCCS Policlinico San Matteo, Pavia, Piazzale Golgi 2, 27100 Pavia, Italia E-mail: I.bogliolo@smatteo.pv.it 
12), the effectiveness of the available drugs (13-15), and the fact that prevention of secondary fractures is an obvious first step in the development of a systematic approach to the FF, it is evident that the treatment of FF is remarkably inadequate worldwide with a $60-95 \%$ therapeutic gap $(12,16)$. In Italy, less than $20 \%$ of patients with femoral FF receive adequate treatment to prevent new fractures and only $50 \%$ of cases remain compliant to treatement. On the contrary, patients without risk factors and without undergoing proper diagnostic tests are treated for OP $(17,18)$. In addition, even though no specific studies have been conducted, in many patients with primary and secondary OP at high risk of developping FF, the prevention of the first fracture is even less taken into account with a significant therapeutic gap. The causes for this important diagnostic-therapeutic gap are several and different: the unclear definition of the disease, the lack of knolewdge of guidelines, the poor communication between specialists and general practitioners (GPs), the difficult follow-up of elderly patients with different comorbidities and therapies $(20,21)$. This has led the International Osteoporosis Foundation (IOF) and the American Society for Bone and Mineral Research (ASBMR) to request the creation and implementation of strategies and management models to improve the identification of subjects with FF and of those at high risk of OP and FF $(12,22)$. From the first call of the IOF Capture the Fracture programme (23) up to now, the most common management models which seem to ensure secondary prevention and reduce the risk of fracture after the Fracture Index (FI) have been the Orthogeriatrics Services, with over $80 \%$ of patients starting treatment for osteoporosis $(24,25)$, and the Fracture Liaison Service (FLS) (26-29). These models have shown an improvement in the management of patients with FF, with a percentage of diagnosed and treated patients reaching $51 \%$, an adherence to 1 -year treatment of $88 \%$ and a rate of new fractures of $2 \%(30,31)$. Recently, the Fragility Fracture Network (FFN) argued that a multidisciplinary and multi-professional global collaboration could be the right step to ensure a systematic approach to the treatment of FF (32). Attempts to manage frail patients have been made also in Italy (33), but only with a partial and limited approach to secondary prevention, which is the most obvious and immediate gap, though only the tip of the iceberg. The pathology behind bone fragility has certainly a more extensive substrate that determines a much wider social and economic impact, which will inevitably increase in the upcoming decades. Therefore, the correct identification and management of patients with FF as well as those at a high risk (5) will be able to guarantee in the future an effective reduction of fractures and a more appropriate and sustainable management of patients with bone fragility.

In Italy, a significant contribution comes from the 2015 revision of the Italian Medicines Agency (AIFA) Note 79 (34) which is intended to identify the highest-risk patients, define the levels of treatment requirements according to severity and select the most appropriate medical treatment, based on criteria of safety, cost-effectiveness, adherence and pathophysiological rationale. For this reason, starting from Note 79 and the FLS model, we propose a management model based on a significant change in the approach to this disease, which focuses on the correct identification of patients with bone fragility by specialists and GPs. The patient is included in a shared diagnostictherapeutic-care path (PDTA), which is based firstly on risk factors and then on severity and complexity to organize the degree of intervention based on severity, complexity and skills. In the PDTA, the GP has the role of clinical manager and controller ensuring the appropriate first or second level diagnostic-therapeutic procedure and avoiding drop-outs.

\section{MATERIALS AND METHODS}

We propose a model with a different mental approach from those used until now. After the analysis of the area of competence, the Bone Specialist (BS) has to search for alliances and spread the culture of bone 
disease. The BS should proactively involve specialists who see fractures due to fragility, but who do not have the skills and knowledge for proper differential diagnosis and therapeutic management. Moreover, BSs must cooperate with GPs, who know their patients' complete medical profiles and, therefore, their pathologies and therapies associated with their bone fragility risk. Following this algorithm, all clinicians have a well-defined role that can be summarized according to the notion of who does what. The key points in the construction of our model are:

1. creation of a real network between clinicians without distinction between GPs and specialists;

2. correct identification of the patient with bone fragility or at risk;

3 . inclusion of the patient with bone fragility, fracture or at high risk, in a shared PDTA;

4. patient management according to the severity levels as defined by the AIFA note 79 ;

5. central role as clinical manager of the GP, facilitating patient management and communication between the various specialists and the BS.

In order to implement a model that could incorporate these key points, various steps have been taken with BSs, specialists and GPs over the years. Below we describe the steps from the creation of a real network up to the joint multidisciplinary management system.

\section{Creating the network}

\section{Characteristics of the territory}

The province of Pavia includes an extensive territory with three health districts with homogeneous age and gender stratification (35): the city of Pavia, the district of Oltrepò Pavese and the district of Lomellina. The largest public hospitals are two: the Azienda Socio Sanitaria Territoriale (ASST-Pavia) (Azienda Ospedaliera - AOPavia- up to 2015) and the Istituto di Ricovero e Cura a Carattere Scientifico (IRCCS) Policlinico San Matteo. ASST-Pavia is a healthcare unit with 8 hospitals and clinics: two Hubs in Voghera and Vigevano and six

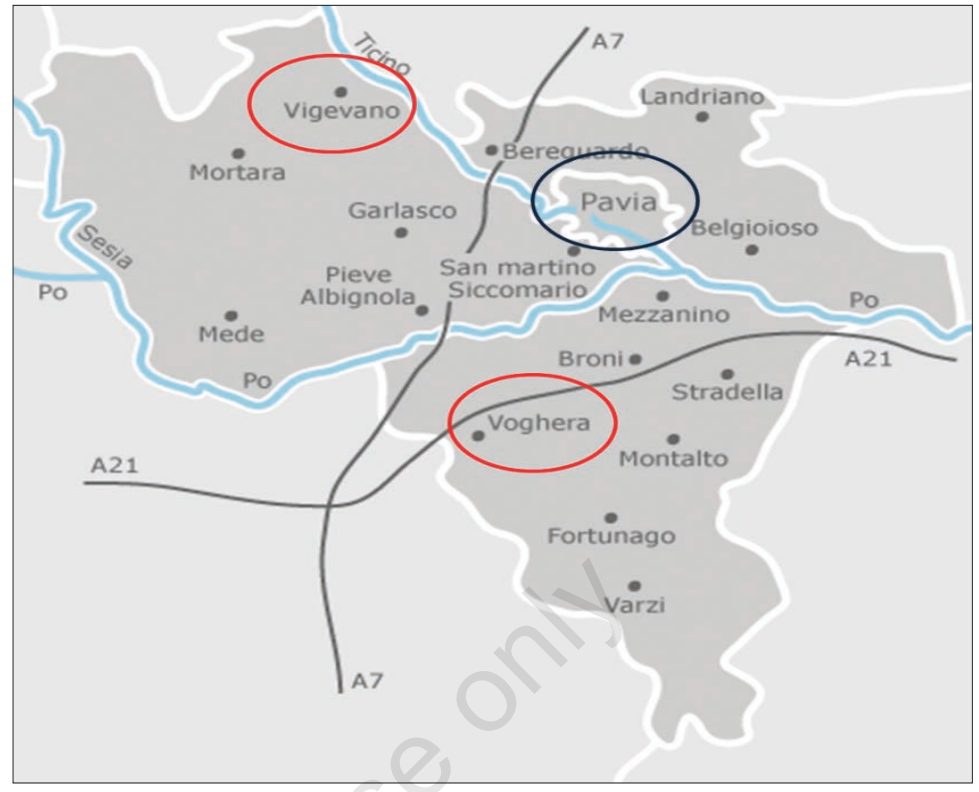

Figure 1 - Territory of the province of Pavia. In Voghera and Vigevano there are the two Hubs of ASST-Pavia with outpatients clinic for severe osteoporosis managed by the bone specialist (red circle); in Pavia there is the osteometabolic outpatient clinic of the San Matteo hospital managed by the bone specialist (black circle).

Spokes in Casorate Primo, Mede, Mortara, Broni, Stradella, Varzi and two clinics in Pavia (Figure 1).

\section{Beginning of the network}

The network was founded in 2009 in the Oltrepò district, where there was the Italian Society for Osteoporosis, Mineral Metabolism and Bone Diseases (SIOMMMS) center with a BS (MCC) belonging to the Complex Operating Unit (UOC) for specialized rehabilitation of the Hospital of Voghera, and some GPs interested in the project. Due to its proximity and the high number of admissions for FF, the Don Gnocchi Foundation of Salice Terme, a private health facility accredited with the National Health Service for rehabilitation, was also involved in the development of the network.

From 2009 to 2016, several educational meetings between BSs (MCC), GPs and other specialists were promoted to spread SIOMMMS guidelines $(5,36)$ and knowledge of the fracture risk algorithms (first Frax and then DeFRA) $(37,38)$, as tools for 
Table I - Educational meetings attended by BSs, GPs and other specialists from 2009 to 2016.

\begin{tabular}{|c|c|c|c|}
\hline Year and place & Title & Specialists involved & Rationale \\
\hline 2009 Oltrepò & $\begin{array}{l}\text { Osteoporosis Outpatient Clinic: } \\
\text { from prevention to therapy: a } \\
\text { reality in Oltrepo }\end{array}$ & $\begin{array}{l}\text { Orthopedics } \\
\text { Physiatrists } \\
\text { GPs }\end{array}$ & $\begin{array}{l}\text { Spreading culture about bone } \\
\text { pathology }\end{array}$ \\
\hline 2010 Oltrepò & $\begin{array}{l}\text { Osteoporosis Oltrepò } \\
\text { Diagnostic therapeutic pathways: } \\
\text { prevention and fracture units }\end{array}$ & $\begin{array}{l}\text { Orthopedics } \\
\text { Physiatrists } \\
\text { GPs }\end{array}$ & $\begin{array}{l}\text { Provide basic knowledge about } \\
\text { the pathology and start to } \\
\text { define appropriate pathways }\end{array}$ \\
\hline 2012 Oltrepò & Secondary osteoporosis & $\begin{array}{l}\text { Bone specialist } \\
\text { Orthopaedic } \\
\text { Physiatrist } \\
\text { Endocrinological } \\
\text { Urologist } \\
\text { Internist } \\
\text { GPs }\end{array}$ & Focus on differential diagnosis \\
\hline 2014 Oltrepò & $\begin{array}{l}\text { Osteoporosis: importance } \\
\text { of hospital out-of-hospital } \\
\text { network risk factors for shared } \\
\text { management of patients with } \\
\text { bone fragility }\end{array}$ & $\begin{array}{l}\text { Bone specialist } \\
\text { Orthopaedic } \\
\text { Physiatrist } \\
\text { Endocrinological } \\
\text { Internist } \\
\text { GPs }\end{array}$ & $\begin{array}{l}\text { Define risk factors for bone } \\
\text { fragility and share management } \\
\text { approach with out-of-hospital } \\
\text { services }\end{array}$ \\
\hline 2015 Oltrepò & $\begin{array}{l}\text { Capture the fractures: } \\
\text { diagnostic-therapeutic } \\
\text { appropriateness in fragility } \\
\text { fractures }\end{array}$ & $\begin{array}{l}\text { Bone specialist } \\
\text { Physiatrist } \\
\text { Orthopaedic } \\
\text { Endocrinologist } \\
\text { Internist } \\
\text { GPs }\end{array}$ & $\begin{array}{l}\text { Focus on fragility fractures, } \\
\text { FLS culture, defining who does } \\
\text { what }\end{array}$ \\
\hline $\begin{array}{l}2016 \text { Lomellina } \\
\text { and Oltrepò }\end{array}$ & $\begin{array}{l}\text { Meetings with Bone Specialists } \\
\text { and out-of-hospital services (three) }\end{array}$ & $\begin{array}{l}\text { Bone Specialist } \\
\text { GPs }\end{array}$ & GPs training \\
\hline
\end{tabular}

a correct differential diagnosis and severity quantification of the disease (Table I). Over the years, the meetings have changed with an increased proactive role of specialists and GPs. Two aspects have emerged from the meetings and the interactions between $\mathrm{BSs}$ and other clinicians: the need to continue to involve specialists and GPs and the standardization of the role of hospital specialists in the definition of the pathology, diagnosis and therapy. Therefore, a progressive intrahospital cooperation between BSs and specialists from different operating units of the OA of Pavia was finally set into action.

\section{Creation of the first Hospital} Therapeutic Diagnostic Path (PDT) in the $A O$ of Pavia

In 2014 the AO of Pavia (ASST-Pavia from 2016) validated a PDT for the management of inpatients and outpatients with FF. The
PDT was created by a multidisciplinary working group composed of quality control staff, orthopaedic specialists, physiatrists and internists. For both inpatients and outpatients the key points of the PDT were: - clinicians' agreement to define the FF, that had to be reported in the discharge letter;

- definition of FF that had to be based on the onset mechanism;

- inclusion of the fractured patient into an ad hoc path, where biohumoral and instrumental examinations were defined for a correct differential diagnosis and severity;

- definition of management levels, different between the UOCs of orthopaedics and physiatrics;

- indication in the discharge letter of antifracture therapy according to AIFA note 79 or reason for non-therapy. 


\section{Creation of the outpatient clinic} dedicated to osteometabolic diseases in the IRCCS Policlinico San Matteo In 2011, the IRCCS Rheumatology UOC needed a more appropriate management of patients with bone fragility. The establishment of a dedicated outpatient clinic meant taking care of the most complex patients, already treated by other IRCCS hospital specialists, with important comorbidities, such as HIV and solid organ transplantation, as well as the patients with rheumatological disorders. Shared management of the most complex patients was started and involved BSs (LB), rheumatologists, infectivologists, pneumologists, nephrologists and physiatrists. Over the years, the outpatient clinic for osteometabolic diseases has taken care of patients with severe OPs already treated by IRCCS or sent by some Operative Units (UO) of the IRCCS for specific diseases at high risk of developping FF.

\section{Hospitals and territorial network and multidisciplinary team}

Thanks to the reform of the Lombardy Region regarding the follow-up of the chron-

Table II - Meetings attended by BSs, GPs and other specialists to define the steps for the path for patients with bone fragility.

\begin{tabular}{|c|c|c|c|}
\hline Year and place & Title & Specialists/Figures involved & Rational \\
\hline 2017 Pavia & $\begin{array}{l}\text { Hospitals and out- } \\
\text { of-hospital services: } \\
\text { synergy for correct } \\
\text { management of the } \\
\text { patient with fragile } \\
\text { bones }\end{array}$ & $\begin{array}{l}\text { Bone specialist } \\
\text { Physiatrist } \\
\text { Orthopaedic } \\
\text { Endocrinologist } \\
\text { Internist } \\
\text { Nephrologist } \\
\text { Rheumatologist } \\
\text { Infectivologist } \\
\text { GPs }\end{array}$ & $\begin{array}{l}\text { Create synergy between } \\
\text { hospitals in the province and } \\
\text { out-of-hospital services }\end{array}$ \\
\hline 2018 Pavia & $\begin{array}{l}\text { PDTA shared hospitals } \\
\text { and out-of-hospital } \\
\text { services for fragility } \\
\text { fracures }\end{array}$ & $\begin{array}{l}\text { Bone specialist } \\
\text { Physiatrist } \\
\text { Orthopaedic } \\
\text { Rheumatologist } \\
\text { Nephrologist } \\
\text { Pneumologist } \\
\text { Gynecologist } \\
\text { Oncologist } \\
\text { Gastroenterologist } \\
\text { Infectivologist } \\
\text { GPs coordinators } \\
\text { Health Director } \\
\text { Facilitator }\end{array}$ & $\begin{array}{l}\text { Creation of a multi } \\
\text { professional and } \\
\text { multispecialty working group, } \\
\text { defining who does what }\end{array}$ \\
\hline 2018 Pavia & $\begin{array}{l}\text { ASST-IRCCS } \\
\text { co-branding for } \\
\text { multidisciplinary } \\
\text { management of } \\
\text { fragility fractures: } \\
\text { PDTA hospitals } \\
\text { and out-of-hospital } \\
\text { services in the } \\
\text { Province of Pavia }\end{array}$ & $\begin{array}{l}\text { Bone specialist } \\
\text { Physiatrist } \\
\text { Orthopaedic } \\
\text { Rheumatologist } \\
\text { Nephrologist } \\
\text { Pneumologist } \\
\text { Gynecologist } \\
\text { Oncologist } \\
\text { Gastroenterologist } \\
\text { Infectivologist } \\
\text { GPs coordinators } \\
\text { Health Director } \\
\text { Case Manager } \\
\text { Representatives of the Quality } \\
\text { and Risk management structure }\end{array}$ & $\begin{array}{l}\text { Definition and validation of the } \\
\text { hospital and out-of-hospital } \\
\text { services PDTA for patients } \\
\text { with osteoporosis and fragility } \\
\text { fractures }\end{array}$ \\
\hline
\end{tabular}


ic patient and the goal to create intra-hospital and territorial alliances, the strategic management departments of ASST and IRCCS of Pavia in June 2016 started a collaboration between the osteoporosis centers of ASST-Pavia and IRCCS San
Matteo of Pavia. The collaboration between the two centres, the two BSs (MCC and $\mathrm{LB}$ ) and the progressive expansion of the network resulted in a multidisciplinary PDTA shared between both the hospitals and the local healthcare facilities, using

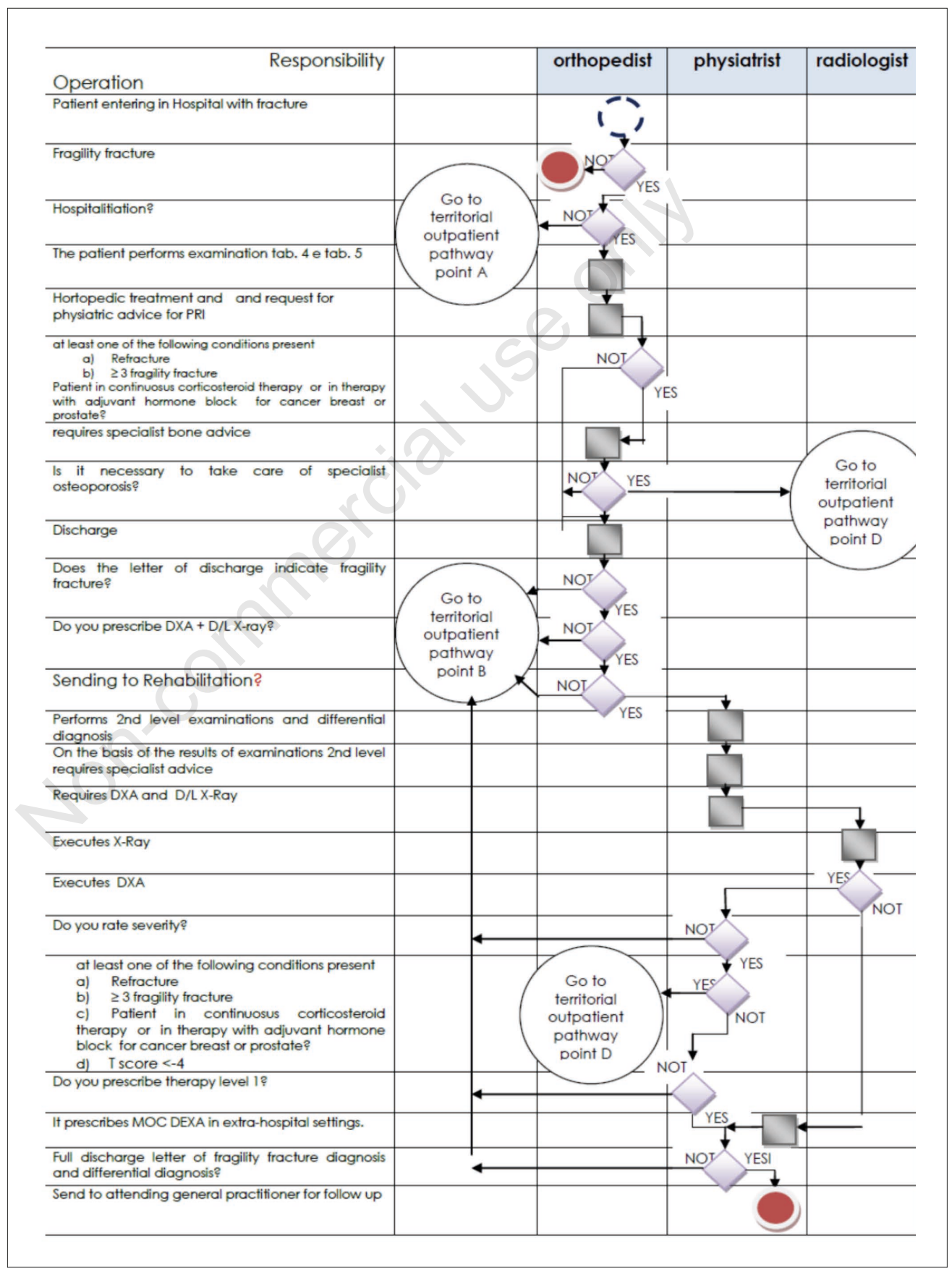

Figure 2A - Summary flow-chart for secondary prevention in patients hospitalized with FF, according to severity levels. 
the AIFA Note 79 as reference algorithm. Therefore, for the creation of the network and the PDTA, we have:

- identified and then involved the specialists who work in ASST and IRCCS and take care of patients at a high risk of fracture: orthopedics, physiatrists, rheumatologists, internists, gastroenterologists, pneumologists, nephrologists, gynaecologists, oncologists, infectivologists;

- promoted 3 events (Table II) to present

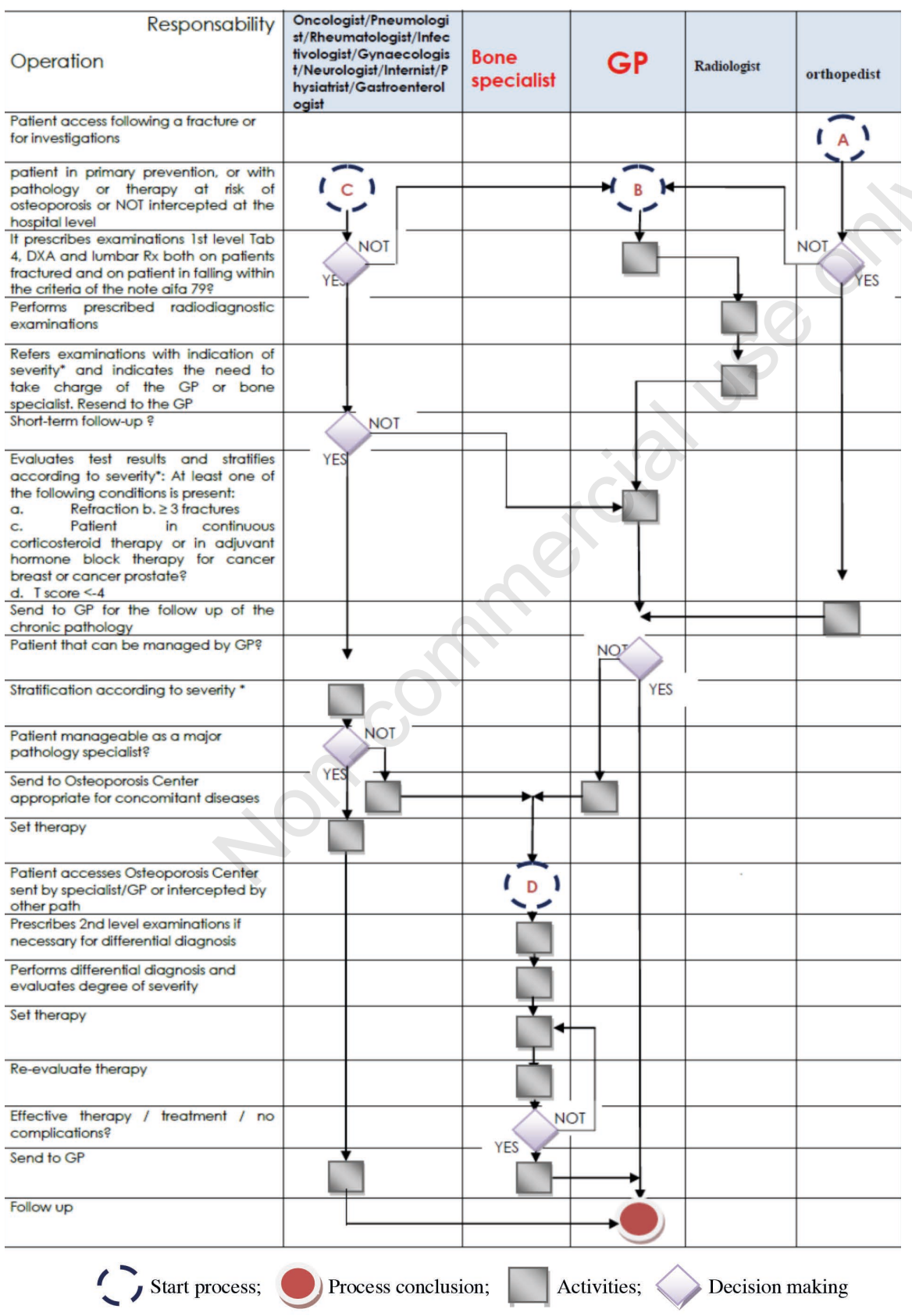

Figure 2B - Summary flow-chart for primary and secondary prevention in outpatients with bone fragility, according to severity levels. 
the PDTA structure to all the specialists involved and to the GPs of the territorial network, in order to discuss the critical issues and decide together who does what according to the skills and the resources of the different UOs and territories.

Between 2016 and 2018 a multidisciplinary team was identified and created with specialists from both ASST and IRCCS, $\mathrm{BS}$ and the collaboration of a nursing case manager.

\section{RESULTS}

In January 2019, the PDTA, coordinated by the two BSs and shared by 25 specialists and 9 GPs, among which one coordinator $(\mathrm{GG})$ and representatives of each territorial district, was validated by the two Health Quality departments (ASST and IRCCS) and authorized by the two Health Directorates (ASST and IRCCS). Figure 2 (A, B) describes the flow chart that summarizes the activities and responsibilities of the different specialists, the GPs and $\mathrm{BSs}$, in the identification of patients, their stratification according to their disease severity and consequently the first level treatment or the referral to the BS. The PDTA describes the rationale, the starting model and the importance of risk factors, I and II level blood tests and imaging assessments to be performed according to SIOMMMS guidelines, the phases of the differential diagnosis and of a correct diagnosis of the severity. It also describes the levels of prevention, both of the OP itself and the FFs, and the steps for GPs and specialists respectively, according to decision-making algorithms shared with the BS (flow-charts not shown). In April 2019, the PDTA was described to GPs at an event organized with the collaboration of the Physicians Association of Pavia, in which 60 GPs supported the management of patients with bone fragility according to the PDTA. On the same occasion, Ossinergy (OssApp) was presented. It is a computer application accessible from personal computer (PC), tablet and smartphone, created to facilitate the path within the decision-making algo- rithms and according to Note AIFA 79. It will be provided free of charge to all GPs who join the PDTA and to the specialists who request it.

\section{DISCUSSION AND CONCLUSIONS}

According to the World Health Organization (WHO) data, Europe is the geographical area most affected by FF (34\% of the 9 million events in the world) (12). Although FF and OP represent a significantly increasing healthcare burden for Europe and Italy, most patients at high risk do not receive medical treatments $(18,29,39)$. It is crucial to deal with this significant therapeutic gap urgently, so that the overall burden, which is personal as well as social, can be reduced $(12,40,41)$. This is particularly relevant for secondary fracture prevention (42). A recent systematic review of the literature reports that the FLS model and the orthogeriatric services are significantly improving in secondary prevention (40). Nevertheless, due to differences in the health systems between and within nations, it is difficult to apply the FLS model tout court. It sems to be more reasonable to grasp the essence of the method and to modulate it according to the different local situations. Nevertheless, it should be considered that the expected increase in the number of OP cases is inevitable, due to the population ageing and growth $(43,44)$, as is the increasing incidence of chronic diseases, often complicated by secondary OP. Therefore, in order to manage patients with bone fragility in a sustainable way, it seems necessary to identify also subjects at high risk of a first FF. In Italy, a guide to properly manage patients with osteoporosis and/or FF is certainly Note 79 (34) on which our PDTA is based, that is intended to identify and capture the highest number of fragile patients and manage them according to severity and complexity of their disease. In order to simplify the process, the OssApp has been created and will be distributed to all GPs. Through the App they can be assisted in differential diagnosis and therapeutic decision making, according to Note 
79. In line with the reform of the Lombardy Region regarding chronic patients (45) and the national plan for chronicity (46), the creation of the network involving GPs, specialists and BSs should lead to a progressive improvement of diagnosis, appropriateness and adherence to the therapy, optimization of resources and consequent reduction of social and economic costs related to fractures due to fragility. We realize that a limit in our model is that we have not considered the recent concept of imminent risk, particularly after hip fracture (47). In the next PDTA revision we will consider an immediate therapeutic approach with drugs that can offer faster action and greater efficacy, regardless of the treatment levels reported in Aifa Note 79. Furthermore, as stated by Ferrari et al. (48), we believe that complete disease management should also include the prevention of osteoporosis as part of a broader and more ambitious project, like the Multidisciplinary Osteoporosis Project Hospitals and Territory (PrOMOTer) (Figure 3).

This project involves coordinated work between GPs and the Health Protection Agency (ATS) of Pavia aimed to: i) identify 30- and 50-year old women mostly at risk of developing OP by means of a modified IOF questionnaire; ii) promote educational events focused on growth and adolescence age in agreement with health institutions, in order to modify the risk factors partially responsible for a reduced peak of the bone mass and its early loss.

In conclusion, we hope that this management model may spread a comprehensive approach to prevention in the Province of Pavia as well as a correct stratification of patients according to risk factors and disease severity and the intervention of the BS on the most severe and/or complex patients with level II therapy. This model should contribute to reduce the incidence of FF and the consequent need for hospitalization, promote a rational redistribution of healthcare, therapeutic and economic resources, improve the economic impact of this pathology, and, last but not least, ensure equal access to healthcare for all patients.

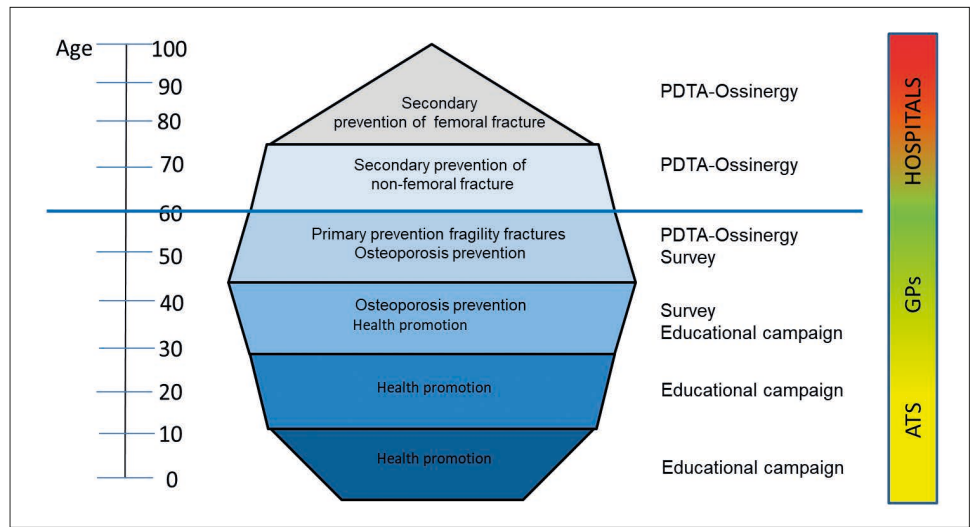

Figure 3 - Multidisciplinary Project Osteoporosis Hospitals and Out-of-Hospital Services (PrOMOTer). GPs: General Practitioners; ATS: Health Protection Agency; PDTA: Therapeutic Care Diagnostic Path.

\section{Contributions}

C.C. Study concept and design, creation of the network and diagnostic-therapeutic path, writing and drafting the manuscript and final approval. B.L. Study concept and design, creation of the network and diagnostic-therapeutic path, writing and drafting the manuscript and final approval. G.G. Study concept and design, creation of the network and diagnostic-therapeutic path, and final approval. S.A. Study concept and design, creation of the network and diagnostictherapeutic path, and final approval. DE. L. Study concept and design and final approal. B.E. Writing and drafting the manuscript and final approval. M. C. Study concept and design, creation of the network and final approval. R. F. Study concept and design, creation of the network and final approval. T.A. Study concept and design, creation of the network and final approval. S.S. Study concept and design, creation of the network and final approval. B.M. Study concept and design, creation of the network. M.A. Creation of the diagnostic-therapeutic path. M.P. Creation of the diagnostic-therapeutic path. R.N. Creation of Ossinergy (OssApp) to guide the diagnostic-therapeutic path. B.M. Study concept and design, creation of the network and final approval.

\section{Competing interests}

All authors have no conflict or competing of interest to declare. 


\section{Acknowledgements}

The authors would like to thank all the 60 GPs who joined the PDTA for their contribution.

\section{REFERENCES}

1. Kanis JA. Assesment of fracture risk and its application to screening postmenopausal osteoporosis: synopsis of a WHO report. WHO Study Group. Osteoporos Int. 1994; 4: 368-81.

2. Melton LJ, Thamer M, Ray NF, et al. Fractures attributable to osteoporosis: report from the National Osteoporosis Foundation. J Bone Miner Res. 1997; 12: 16-23.

3. Colon-Emeric C, Kuchibhatla M, Piper C, et al. The contribution of hip fracture to risk of subsequent fractures: data from two longitudinals studies. Osteoporos Int. 2003; 14: 879-83.

4. Keene GS, Parker MJ, Pryor GA. Mortality and morbidity after hip fractures. BMJ 1993; 307: 1248-50.

5. Rossini M, Adami S, Bertoldo F, et al. Guidelines for the diagnosis, prevention and management of osteoporosis. Reumatismo. 2016; 68: 1-39.

6. Piscitelli P, Iolascon G, Argentiero A, et al. Incidence and costs of hip fractures vs strokes and acute myocardial infarction in Italy: comparative analysis based on national hospitalization records. Clin Interv Aging. 2012; 7: 575-83.

7. Piscitelli P, Brandi M, Cawston H, et al. Epidemiological burden of postmenopausal osteoporosis in Italy from 2010 to 2020: estimations from a disease model. Calcif Tissue Int. 2014; 95: 419-27.

8. Fragility Fractures in Italy. Burden, management and opportunities: EU6 Summary Final report 2018-06-26. Available from: http:// share.iofbonehealth.org/EU-6-Materila/PressReleases/Broken-Bones-Broken-Lives-Pressrelease-ITALY.pdf

9. Johnell O, Kanis JA. An estimate of the worldwide prevalence, disability and mortality associated with hip fracture. Osteoporos Int. 2004; 15: 897-902.

10. Johnell O, Kanis JA. An estimate of the worldwide prevalence and disability associated with osteoporotic fractures. Osteoporos Int. 2006; 17: 1726-33.

11. Odén A, McCloskey EV, Johansson H, Kanis JA. Assessing the impact of osteoporosis on the burden of hip fractures. Calcif Tissue Int. 2013; 92: 42-9.

12. Hernlund E, Svedbom A, Ivergård $M$, et al. Osteoporosis in the European Union: medical management, epidemiology and economic burden. A report prepared in collaboration with the International Osteoporosis Founda- tion (IOF) and the European Federation of Pharmaceutical Industry Associations (EFPIA). Arch Osteoporos. 2013; 8: 136.

13. Murad MH, Drake MT, Mullan RJ, et al. Clinical review. Comparative effectiveness of drug treatments to prevent fragility fractures: a systematic review and network meta-analysis. J Clin Endocrinol Metab. 2012; 97: 1871-80.

14. Degli Esposti L, Girardi A, Saragoni S, et al. Use of antiosteoporotic drugs and calcium/vitamin D in patients with fragility fractures: impact on re-fracture and mortality risk. Endocrine. 2019; 64: 367-77.

15. Simpson EL, Martyn-St James M, Hamilton J, Wong R, Gittoes N, Selby P, et al. Clinical effectiveness of denosumab, raloxifene, romosozumab, and teriparatide for the prevention of osteoporotic fragility fractures: A systematic review and network meta-analysis. Bone. 2020; 130: 115081 .

16. Aizer J \& Bolster MB. Fracture Liaison Services: Promoting Enhanced Bone Health Care. Curr Rheumatol Rep. 2014; 16: 455.

17. Degli Esposti L, Sinigaglia L, Rossini M, et al. Adherence to therapeutic and diagnostic recommendations in patients with femur fracture and at risk of re-fracture or death: results of an analysis of administrative databases. Reumatismo. 2012; 64: 18-26.

18. The Medicines Utilisation Monitoring Centre. National Report on Medicines use in Italy. Year 2015. Rome: Italian Medicines Agency, 2016. Available from: https://www.aifa.gov.it/ sites/default/files/OsMed_2015_Eng.pdf; http://www.agenziafarmaco.gov.it/sites/default/files/Rapporto_OsMed_2015_AIFA.pdf

19. Harvey NC, McCloskey EV, Mitchell PJ, et al. Mind the (treatment) gap: a global perspective on current and future strategies for prevention of fragility fractures. Osteoporos Int. 2017; 28: 1507-29.

20. Marsh D, Akesson K, Beaton DE; the IOF CSA Fracture Working Group. Fracture Working Group Coordinator-based systems for secondary prevention in fragility fracture patients. Osteoporos Int. 2011; 22: 2051-65.

21. Kanis JA, Svedbom A, Harvey N, McCloskey EV. The osteoporosis treatment gap. J Bone Miner Res. 2014; 29: 1926-8.

22. Javaid MK, Kyer C, Mitchell PJ, et al. Effective secondary fracture prevention: implementation of a global benchmarking of clinical quality using the IOF Capture the Fracture ${ }^{\circledR}$ Best Practice Framework tool. Osteoporos Int. 2015; 26: 2573-8.

23. Akesson K, Marsh D, Mitchell PJ, et al. Capture the Fracture: a Best Practice Framework and global campaign to break the fragility fracture cycle. Osteoporos Int. 2013; 24: 2135-52.

24. Hawkes D, Baxter J, Bailey C, et al. Improving the care of patients with a hip fracture: a 
quality improvement report. BMJ. 2015; 24: 532-8.

25. Middleton M, Wan B, da Assunçao R. Improving hip fracture outcomes with integrated orthogeriatric care: a comparison between two accepted orthogeriatric models. Age Ageing. 2017; 46: 465-70.

26. Gallacher SJ. Setting up an osteoporosis fracture liaison service: background and potential outcomes. Best Pract Res Clin Rheumatol. 2005; 19: 1081-94.

27. Eekman DA, van Helden SH, Huisman AM, et al. Optimizing fracture prevention: the fracture liasion service an observational study. Osteoporos Int. 2014; 25: 701-9.

28. Falls and Fragility Fracture Audit Programme (FFFAP). National Hip Fracture Database (NHFD) annual report 2015. Available from: https://www.nhfd.co.uk/nhfd/nhfd2015reportPR1.pdf

29. Geusens P, Bours SPG, Wyers CE, van den Bergh JP. Fracture Liaison programs. Best Pract Res Clin Rheumatol. 2019; 33: 278-89.

30. Eisman JA, Bogoch ER, Dell R, et al. ASBMR Task Force on Secondary Fracture Prevention. Making the first fracture the last fracture: ASBMR task force report on secondary fracture prevention. J Bone Miner Res. 2012; 27: 2039-46.

31. Pioli G, Bendini C, Pignedoli P, et al. Orthogeriatric co-management - managing frailty as well as fragility. Injury. 2018; 49: 1398-402.

32. Dreinhöfer KE, Mitchell PJ, Bégué T, et al.; on behalf of the Fragility Fracture Network (FFN), the European Geriatric Medicine Society (EuGMS), the European Federation of $\mathrm{Na}$ tional Associations of Orthopaedics and Traumatology (EFORT), the International Collaboration of Orthopaedic Nursing (ICON), the International Geriatric Fracture Society (IGFS), the International Osteoporosis Foundation (IOF). A global call to action to improve the care of people with fragility fractures. Injury. 2018; 49: 1393-7.

33. Baroni M, Serra R, Boccardi V, et al. The orthogeriatric comanagement improves clinical outcomes of hip fracture in older adults. Osteoporos Int. 2019; 30: 907-16.

34. Modifiche alla Nota 79 di cui alla Determinazione del 7 giugno 2011. Available from: http://www.aifa.gov.it/content/nota-79

35. Statistiche Pavia. Available from: https://www. tuttitalia.it/lombardia/56-pavia/statistiche

36. Adami S, Romagnoli E, Carnevale V, Scillita- ni A, Giusti A, Rossini M, et al. Guidelines on prevention and treatment of vitamin D deficiency. Reumatismo. 2011; 63: 129-47.

37. Kanis JA, Johnell O, Oden A, et al. FRAX ${ }^{\mathrm{TM}}$ and the assessment of fracture probability in men and women from the UK. Osteoporos Int. 2008; 19: 385-97.

38. Adami S, Bianchi G, Brandi M, Di Munno O, Frediani B, Gatti D, et al. Validation and further development of the WHO 10-year fracture risk assessment tool in Italian postmenopausal women: project rationale and description. Clin Exp Rheumatol. 2010; 28: 561-70.

39. Cooper C, Ferrari S. IOF Compendium of Osteoporosis. In Harvey N, Dennison E, editors. 1st ed. Nyons: International Osteoporosis Foundation. 2019.

40. Mitchell PJ, Cooper C, Fujita M, et al. Quality Improvement Initiatives in Fragility Fracture Care and Prevention. Curr Osteoporos Rep. 2019; 17: 510-20.

41. EU Report. Available from: http://share.iofbonehealth.org/EU-6-Material/Reports/ IOF\%20Report_EU.pdf

42. Keshishian A, Boytsov N, Burge R, et al. Examining the treatment gap and risk of subsequent fractures among females with a fragility fracture in the US Medicare population. Osteoporos Int. 2017; 28: 2485-94.

43. United Nations Department of Economic and Social Affairs Population Division. World Population Prospects: The 2017 Revision, Key Findings and Advance Tables. Working Paper No. ESA/P/WP.248. New York; 2017.

44. In historic first, G20 weighs ageing as global risk. 2019. Available from: https://www. france24.com/en/20190609-historic-first-g20weighsageing-global-risk Accessed: 29 Sept 2019.

45. Regione Lombardia, Norme. Available from: http://normelombardia.consiglio.regione.lombardia.it/NormeLombardia/Accessibile/main.as px? view $=$ showdoc\&iddoc $=1 \mathrm{r} 002015081100023$

46. Ministero della Salute. Available from: http:// www.salute.gov.it/imgs/C_17_pubblicazioni_2584_allegato.pdf

47. Balasubramanian A, Zhang J, Chen L, et al. Risk of subsequent fracture after prior fracture among older women. Osteoporos Int. 2019; 30: 79-92.

48. Ferrari S, Reginster JY, Brandi ML, et al. Unmet needs and current and future approaches for osteoporotic patients at high risk of hip fracture. Arch Osteoporos. 2016; 11: 37. 